\title{
Estradiol-induced regulation of GLUT4 in 3T3-L1 cells: involvement of ESR1 and AKT activation
}

\author{
Raquel S Campello', Luciana A Fátima1, João Nilton Barreto-Andrade1, \\ Thais F Lucas², Rosana C Mori', Catarina S Porto² and Ubiratan F Machado'1
}

1Department of Physiology and Biophysics, Institute of Biomedical Sciences, University of São Paulo, São Paulo, Brazil 2Section of Experimental Endocrinology, Department of Pharmacology, Escola Paulista de Medicina,

Universidade Federal de São Paulo, São Paulo, Brazil

Correspondence should be addressed to U F Machado Email

ubiratan@icb.usp.br

\begin{abstract}
Impaired insulin-stimulated glucose uptake involves reduced expression of the GLUT4 (solute carrier family 2 facilitated glucose transporter member 4, SLC2A4 gene).

$17 \beta$-estradiol $\left(E_{2}\right)$ modulates SLC2A4/GLUT4 expression, but the involved mechanisms are unclear. Although $E_{2}$ exerts biological effects by binding to estrogen receptors 1/2 (ESR1/2), which are nuclear transcriptional factors; extranuclear effects have also been proposed. We hypothesize that $\mathrm{E}_{2}$ regulates GLUT4 through an extranuclear ESR1 mechanism. Thus, we investigated the effects of $E_{2}$ upon (1) subcellular distribution of ESRs and the proto-oncogene tyrosine-protein kinases (SRC) involvement; (2) serine/ threonine-protein kinase (AKT) activation; (3) S/c2a4/GLUT4 expression and (4) GLUT4 subcellular distribution and glucose uptake in 3T3-L1 adipocytes. Differentiated 3T3-L1 adipocytes were cultivated or not with $E_{2}$ for $24 \mathrm{~h}$, and additionally treated or not with ESR1-selective agonist (PPT), ESR1-selective antagonist (MPP) or selective SRC inhibitor (PP2). Subcellular distribution of ESR1, ESR2 and GLUT4 was analyzed by immunocytochemistry; S/c2a4 mRNA and GLUT4 were quantified by qPCR and Western blotting, respectively; plasma membrane GLUT4 translocation and glucose uptake were analyzed under insulin stimulus for $20 \mathrm{~min}$ or not. $\mathrm{E}_{2}$ induced (1) translocation of ESR1, but not of ESR2, from nucleus to plasma membrane and AKT phosphorylation, effects mimicked by PPT and blocked by MPP and PP2; (2) increased S/c2a4/GLUT4 expression and (3) increased insulin-stimulated GLUT4 translocation and glucose uptake. In conclusion, $\mathrm{E}_{2}$ treatment promoted a SRC-mediated nucleus-plasma membrane shuttle of ESR1, and increased AKT phosphorylation, S/c2a4/GLUT4 expression and plasma membrane GLUT4 translocation; consequently, improving insulin-stimulated glucose uptake. These results unravel mechanisms through which estrogen improves insulin sensitivity.
\end{abstract}

Journal of Molecular Endocrinology (2017) 59, 257-268

\section{Introduction}

Type 2 diabetes mellitus (T2DM) is characterized by disruption of glycemic homeostasis, involving impaired insulin-induced glucose uptake (Björnholm \&
Zierath 2005), in which reduced expression of the solute carrier family 2 of facilitated glucose transport member 4 (GLUT4) plays a fundamental role. This transporter, 
encoded by the solute carrier family 2 member 4 gene (SLC2A4), is highly expressed in skeletal muscle and adipose tissue. GLUT4 translocates from intracellular microsomes to the cell surface in response to insulin, by means of a phosphatidylinositol 3-kinase (PI3K)and serine/threonine-protein kinase (AKT)-mediated pathway (Tsuchiya et al. 2013), increasing glucose uptake in these tissues (Watson \& Pessin 2001). Thus, although SLC2A4/GLUT4 expression is an essential element for tissue glucose disposal (Corrêa-Giannella \& Machado 2013), it also depends on GLUT4 translocation, and disruption on this pathway may be related to impaired glucose uptake.

$17 \beta$-estradiol $\left(\mathrm{E}_{2}\right)$ is a steroid hormone, primarily known for its role in female physiology and reproduction. Nevertheless, $\mathrm{E}_{2}$ has played other physiological roles in both males and females, such as the control of glycemic homeostasis. Insulin resistance has been related to low estrogen levels in males (Smith et al. 1994, FaustiniFustini et al. 1999); to both low and high estrogen levels in females (Solomon et al. 2001, Meyer et al. 2011) and to the pathogenesis of T2DM (Solomon et al. 2001, Meyer et al. 2011). Slc2a4/GLUT4 expression was observed to be reduced in muscle cells treated with $10^{-8} \mathrm{M} \mathrm{E}_{2}$ for $24 \mathrm{~h}$ (Barros et al. 2008), which could contribute to the $\mathrm{E}_{2}$-related insulin resistance; however, this effect in adipocytes is not clearly known.

Estrogens exert their main biological effects by binding to estrogen receptors 1 and 2 (ESR1 and ESR2), previously described as ER $\alpha$ and ER $\beta$, respectively. ESRs are widely distributed throughout the body, exhibiting tissue- and cell-type-specific expression (Heldring et al. 2007, Nilson \& Gustafsson 2011). In adipose tissue and skeletal muscle, both isoforms are expressed (Barros et al. 2006a, 2008, Campello et al. 2012a) in a distinct grade: ESR1 predominating in adipose tissue, whereas ESR2 in skeletal muscle (Barros et al. 2009).

The classical mechanism of $\mathrm{E}_{2}$ action occurs via nuclear ESRs that directly bind to specific estrogenresponsive elements (EREs) in the promoter region of target genes (Heldring et al. 2007). Moreover, nuclear ESRs can modulate the expression of genes lacking the EREs, through interaction with other transcriptional factors (Krishnan et al. 1994, Galien \& Garcia 1997). Regarding that, NFKB has already been demonstrated as involved in the ESR1/ESR2-mediated modulation of the Slc2a4 gene expression in adipocytes (Campello et al. 2012a).

In addition to these well-established genomic actions, there is evidence that $\mathrm{E}_{2}$ also exerts extranuclear effects. These effects are mediated by (1) classical ESRs situated at or proximal to the plasma membrane (Levin 2014); (2) alternative spliced forms of ESR1 (ER $\alpha-46$ and ER $\alpha-36)$ (Kang et al. 2010) and/or (3) G protein-coupled estrogen receptor (GPER1) (Prossnitz \& Barton 2014). These extranuclear effects involve intracellular signals, such as activation of the PI3K/AKT pathway (Lucas et al. 2008, Garrido et al. 2013).

ESRs are known to be constantly shuttling between the cytoplasm and nucleus. Under steady-state conditions, ESRs have been predominantly detected in the nucleus, but the ESRs traffic in and out the plasma membrane has been described as well (Dauvois et al. 1993). A growing body of evidence demonstrates that the mechanisms responsible for ESR1 plasma membrane localization include posttranslational modifications of the receptor, such as palmitoylation and phosphorylation, followed by assembly of a protein complex with some membraneassociated proteins (Acconcia et al. 2005, Castoria et al. 2012, Adlanmerini et al. 2014). In this process, several proteins such as those from the SRC family (protooncogene tyrosine-protein kinases) are implicated. $\mathrm{E}_{2}$ can induce SRC-mediated phosphorylation of ESR1, thus inducing its nuclear exclusion and consequent translocation to plasma membrane (Lucas et al. 2008, Castoria et al. 2012).

On the other hand, the $\mathrm{E}_{2}$-induced ESR1 translocation to the plasma membrane and/or its surroundings has been described to promote ESR1/PI3K interaction, thus increasing AKT activity (Simoncini et al. 2000). Importantly, since PI3K/AKT participates in the insulin signaling pathway, plasma membrane ESR1 must play a significant role in insulin-sensitive tissues. In fact, modulations of insulin-induced glucose uptake in response to $\mathrm{E}_{2}$ have been described in adipocytes; however, in a controversial dose-dependent pattern (Collison et al. 2000, Muraki et al. 2006, Nagira et al. 2006). Additionally, there is evidence that ESR1-mediated $\mathrm{E}_{2}$ effect also alters the insulin receptor substrate IRS1 activity, upstream of the PI3K/AKT activation (Muraki et al. 2006, Nagira et al. 2006). However, contradictorily, the increased $10 \mathrm{nM} \mathrm{E}_{2}$-induced IRS1/PI3K/AKT activity was observed concomitantly with ESR1 nuclear restraint (Nagira et al. 2006).

Altered skeletal muscle GLUT4 expression and glycemic homeostasis in ESR1-/- and ESR2-/- strongly suggests GLUT4 might be regulated by $\mathrm{E}_{2}$. Overall, it seems that $\mathrm{E}_{2}$, through an ESR1-mediated mechanism, might regulate insulin-induced glucose disposal in adipocytes; however, the accurate effect, as well as the GLUT4-related mechanisms, are yet unknown. Thus, this study attempted

Published by Bioscientifica Ltd 
to investigate the effects of $\mathrm{E}_{2}$ upon: (1) the subcellular distribution of ESRs and SRC protein involvement; (2) the AKT activation and (3) the GLUT4 subcellular distribution and consequent glucose uptake in 3T3-L1 adipocytes.

\section{Materials and methods}

\section{T3-L1 Cell culture}

Mouse 3T3-L1 fibroblasts were obtained from American Type Culture Collection, Rio de Janeiro Cell Bank, Rio de Janeiro, RJ, Brazil (ATCC Number: CL-173TM). Cells were propagated and differentiated as previously described (Campello et al. 2012a, Furuya et al. 2013). Fully differentiated cells were starved in DMEM without phenol red (Sigma-Aldrich) and with FBS (10\%) treated with dextran carbon (Sigma-Aldrich) for $24 \mathrm{~h}$ prior to treatment. Cells were subjected to differentiation at passages 8-10.

\section{Cell treatments}

Differentiated adipocytes were treated for $24 \mathrm{~h}$ in the absence $\left(\mathrm{OE}_{2}\right)$ or presence $\left(10 \mathrm{E}_{2}\right)$ of $10 \mathrm{nM}$ water-soluble $17 \beta$-estradiol ( $\mathrm{E}_{4} 389$; Sigma-Aldrich); added or not with (1) $10 \mathrm{nM}$ of PPT, a selective ESR1 agonist $\left(4,4^{\prime}, 4^{\prime \prime}\right.$-(4-propyl[1H]-pyrazole-1,3,5-triyl)trisphenol; $\quad$ Sigma-Aldrich); (2) $1 \mu \mathrm{M}$ of MPP, a selective ESR1 antagonist (1,3-bis (4-hydroxyphenyl)-4-methyl-5-(4-(2-piperidinylethoxy) phenol)-1H-pyrazole dihydrochloride; Tocris, Bristol, UK); (3) $10 \mathrm{nM}$ of G15, a selective inhibitor of GPER1, $\left(\left(3 \mathrm{a} S^{*}, 4 R^{*}, 9 \mathrm{~b} R^{*}\right)\right.$-4-(6-bromo-1,3-benzodioxol-5-yl)$3 \mathrm{a}, 4,5,9 \mathrm{~b}-3 \mathrm{H}$-cyclopenta[c]quinoline; Tocris) or (4) $10 \mathrm{nM}$ PP2, a selective inhibitor of the SRC family of protein tyrosine kinases (4-amino-5-(4-chlorophenyl)-7-(t-butyl) pyrazolo(3,4-d)pyrimidine; Calbiochem) (Konigame et al. 2011, Campello et al. 2012a). PPT and PP2 were solubilized in DMSO; then, when these compounds were used, DMSO was added to all experimental conditions at the same final concentration (0.1\%). Additional studies were performed in cells starved from FBS in the last $3 \mathrm{~h}$ of treatments, to remove any insulin effect, and then stimulated or not with $17 \mathrm{nM}$ insulin (Humulin R, Eli Lilly Brazil, São Paulo, Brazil) for 20 min (Campello et al. 2012a).

\section{2-deoxi-D-[3H]glucose (2-DG) uptake}

2-DG uptake assay was performed as previously described, and results were expressed as $\mathrm{pmol} / \mathrm{mg}$ protein/min (Campello et al. 2012b).

\section{Analysis of SIc2a4 mRNA and GLUT4 protein}

Slc2a 4 mRNA was analyzed by real-time PCR and GLUT4 protein by Western blotting, as previously described (Campello et al. 2012a). Total cellular GLUT4 was measured in cells homogenate, using actin cytoplasmic 1 protein (ACTB) as loading control. Additionally, subcellular fractionation was performed to obtain plasma membrane (PM)-enriched fraction, to quantify the GLUT4 translocation. The efficiency of this fractionation was previously confirmed: the PM fraction recovers $~ 85 \%$ of the total cellular 5'nucleotidase activity, a plasma membrane marker (Campello et al. 2012b), and in vivo insulin-induced GLUT4 increase in PM and decrease in microsomal fraction (M) were clearly observed by Western blotting. The Ponceau-stained nitrocellulose membranes were used as loading control for PM and M GLUT4 measurement (Romero-Calvo et al. 2010).

\section{Analysis of Esr1 and Esr2 mRNA}

Differentiated 3T3-L1 cells were lysed in TRIzol reagent (Thermo Scientific, \#15596). Total RNA was extracted with phase separation reagent (BCP) (MRC, \#151) and RNeasy kit (Qiagen, \#74104), and reverse transcription was performed using the High-Capacity cDNA Reverse Transcription kit (Applied Biosystems, \#4387406), according to manufacturer's instructions. TaqMan Universal Mastermix II (Applied Biosystems, \#4440038) and assays Mm00433149_m1 and Mm00599821_m1 were used for amplification of Esr1 and Esr2; respectively, in a QuantStudio 12K Flex Real-Time PCR System machine. Relative expression values were calculated from the threshold cycle (Ct) following the 2- $\Delta \Delta C T$ method and using Gapdh (Mm99999915_g1) as an internal reference gene.

\section{ESR1/2 and GLUT4 cellular localization}

Immunofluorescence analysis of ESR1, ESR2 and GLUT4 was performed as previously described (Barros et al. 2006b, Lucas et al. 2008). Briefly, 3T3-L1 cells were grown and differentiated on glass coverslips coated with gelatin $(0.1 \%)$. After blocking, cells were incubated with one of the following primary antibodies: rabbit polyclonal antibody anti-ESR1 (MC-20, Santa Cruz Biotechnology) diluted at 1:50, goat polyclonal antibody anti-ESR2 (L-20, Santa Cruz) diluted at 1:50 and rabbit polyclonal anti-GLUT4 antibody (07-1404, EMD Millipore) diluted at $1: 100$, in PBS containing $0.01 \%$ saponin and $1 \%$ BSA

Published by Bioscientifica Ltd 
for $1 \mathrm{~h}$ at room temperature. The appropriate Alexa Fluor 594-labeled secondary antibody (Molecular Probes) was used at a final concentration of 1:300. Afterwards, the slides were incubated with nuclear marker (DAPI) (SigmaAldrich) and wheat germ agglutinin (WGA) (SigmaAldrich). Negative control slides were analyzed in the absence of primary antibody. Images were obtained as previously described (Lucas et al. 2008).

\section{Total AKT and phospho-AKT protein analysis}

Total AKT and phospho-AKT were measured in a cellular lysate as previously described (De Castro Barbosa et al. 2013). Membranes were firstly probed with antibody anti p-AKT1/2/3 (p-AKT1/2/3, sc-7985-R, Santa Cruz Biotechnology); secondly, reprobed with antibody antitotal AKT1/2/3 (AKT1/2/3-H-136, sc-8312, Santa Cruz Biotechnology), and finally, reprobed with antibody anti-actin cytoplasmic 1 protein (ACTB) (monoclonal anti-beta-actin, A2228, Sigma-Aldrich). To analyze insulin-stimulated cells, $15 \mu \mathrm{g}$ of protein was loaded for electrophoresis, whereas to analyze cells not exposed to insulin, $50 \mu \mathrm{g}$ of protein was loaded. Results of total AKT and p-AKT were firstly normalized by the internal control ACTB; thus, p-AKT was related to total AKT.

\section{Data analysis}

Results were expressed as mean \pm standard error of mean (s.E.M.) and compared by two-way ANOVA (Bonferroni post-test) or by one-way ANOVA (Newman-Keuls posttest) as indicated. When only two groups were compared, parametric (unpaired Student $t$ ) or nonparametric (MannWhitney) tests were used by comparing the variances, as indicated in legends of figures.

\section{Results}

\section{$E_{2}$ enhances S/c2a4/GLUT4 expression}

To investigate the effects of $E_{2}$ upon glucose disposal in adipocytes, we firstly investigated the glucose transporter expression (Fig. 1A and B). Treatment of 3T3-L1 adipocytes with $10 \mathrm{nM} \mathrm{E}_{2}$ for $24 \mathrm{~h}$ increased both Slc2a4 mRNA and the total cellular GLUT4 protein $\left(P<0.001 \mathrm{vs}^{0 \mathrm{E}_{2}}\right)$.

\section{$E_{2}$ stimulates GLUT4 translocation to plasma membrane and increases insulin-induced glucose uptake}

GLUT4 subcellular localization was initially analyzed by immunocytochemistry. As shown in Fig. 1C, insulin induced an evident GLUT4 translocation to the plasma membrane in the absence of $\mathrm{E}_{2}\left(\mathrm{OE}_{2}(+)\right)$. Surprisingly, the plasma membrane GLUT4 content also increased in response to $E_{2}$, even in the absence of insulin $\left(10 \mathrm{E}_{2}\right.$ $(-))$, and that was further enhanced in the presence of insulin $\left(10 \mathrm{E}_{2}(+)\right)$.

To quantify the GLUT4 translocation, Western blotting analysis of GLUT4 in plasma membrane fraction was performed (Fig. 2A and B). Plasma membrane GLUT4 content was clearly increased by insulin and $\mathrm{E}_{2}$. Two-way ANOVA revealed that both $\mathrm{E}_{2}(P=0.0006)$ and insulin $(P<0.0001)$ have independent (no interaction $P=0.6022)$ positive effects upon GLUT4 translocation to PM (Fig. 2B). Furthermore, the Bonferroni post-test confirmed that $10 \mathrm{E}_{2}$ treatment increased $(P<0.05)$ the GLUT4 translocation to plasma membrane independently of the insulin stimulus.

Thus, the 2-DG uptake was investigated (Fig. 2C), and the results were in accordance with the GLUT4 subcellular distribution. Two-way ANOVA revealed that cellular glucose disposal increased in response to both $\mathrm{E}_{2}$ $(P=0.0214)$ and insulin $(P<0.0001)$ and that there is no interaction between these variables $(P=0.1062)$. However, the Bonferroni post-test revealed a significant $10 \mathrm{nM} \mathrm{E}_{2}$ effect on 2-DG uptake only under the insulin-stimulated condition $(P<0.05)$.

\section{$E_{2}$ induces ESR1 translocation to plasma membrane}

Figure 3 shows the subcellular localization of ESR1 (Fig. 3A) and ESR2 (Fig. 3B). Under basal condition, that is, in the absence of $\mathrm{E}_{2}\left(\mathrm{OE}_{2}\right)$, we detected specific staining for ESR1 and ESR2 mainly in the nuclei of 3T3-L1 adipocytes. After 24-h treatment with $10 \mathrm{nM} \mathrm{E}_{2}\left(10 \mathrm{E}_{2}\right)$, ESR1 was highly detected in plasma membranes, as confirmed by the co-localization of ESR1 and WGA (plasma membrane marker). This $\mathrm{E}_{2}$ effect was not observed for ESR2, which clearly remained in the nuclei. These results show that the ESR1, but not ESR2, translocates from nucleus to plasma membrane upon $\mathrm{E}_{2}$ treatment of adipocytes.

We also examined the relative expression of Esr1 and Esr2 mRNAs in differentiated 3T3-L1 adipocytes. As we can observe (Fig. 3C), Esr1 mRNA content was 10-fold higher than Esr2 mRNA content, suggesting that the ESR1 protein is more abundant in this cell.

\section{Translocation of ESR1 is also induced by PPT and blocked by MPP and PP2}

Figure 3D shows that PPT (ESR1-selective agonist) could induce ESR1 translocation to plasma membrane, in the

Published by Bioscientifica Ltd. 


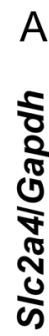

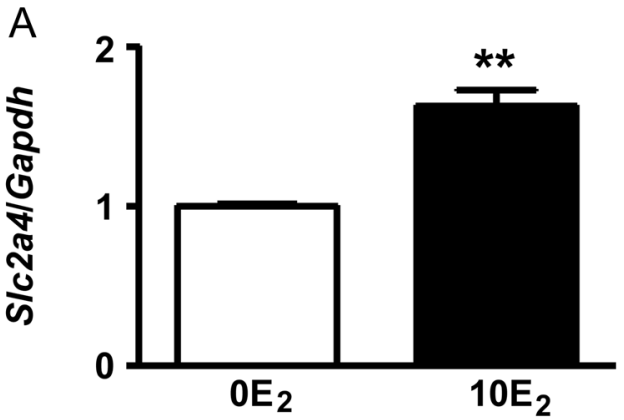

C GLUT4
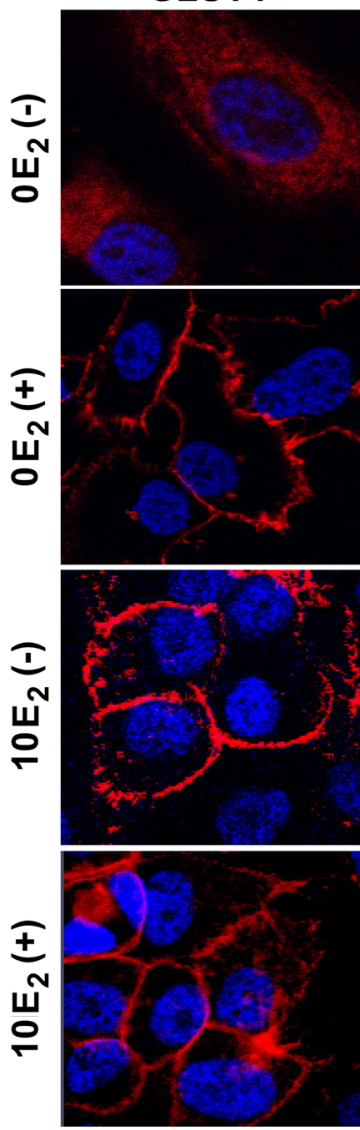

WGA
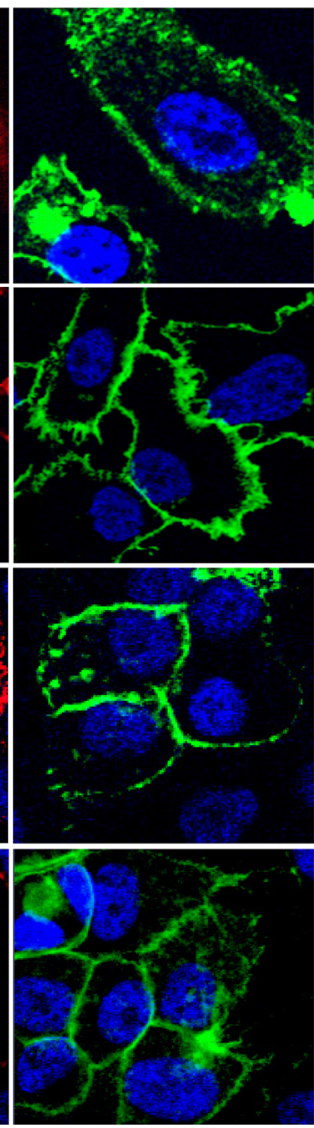

Merged

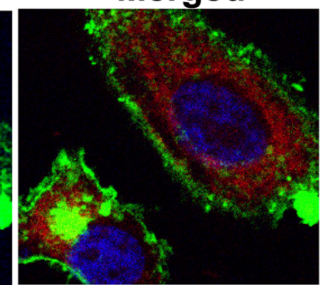

B

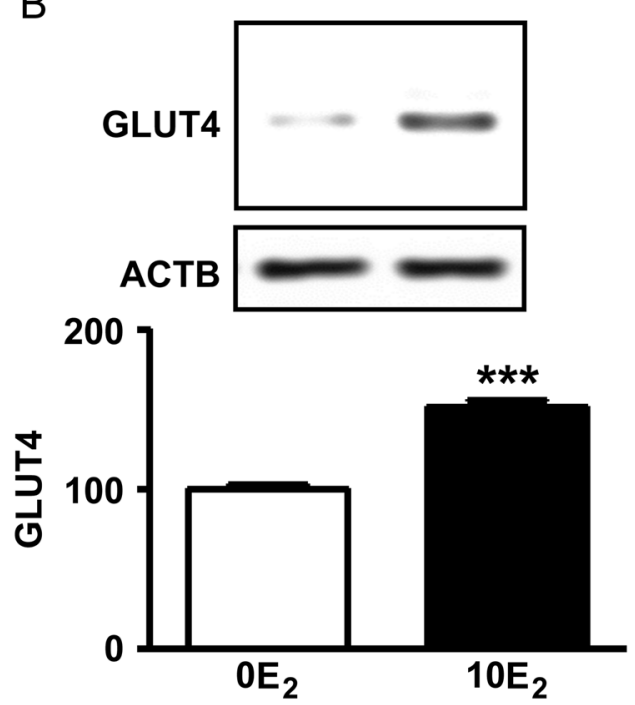

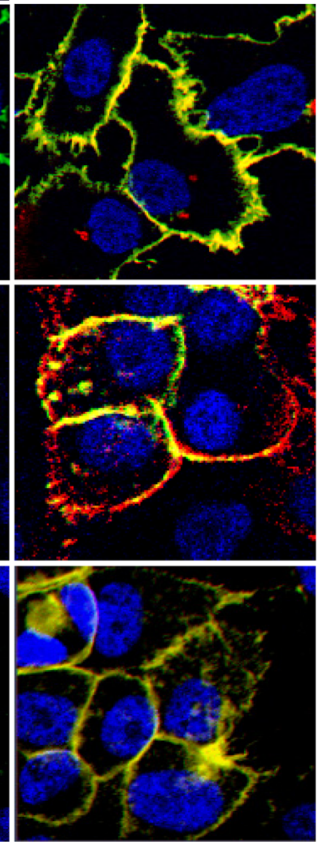

$\overline{20 \mu \mathrm{m}}$

Figure 1

$\mathrm{E}_{2}$ enhances SIc2a4/GLUT4 expression and GLUT4 translocation. Adipocytes were cultivated in the absence $\left(0 \mathrm{E}_{2}\right)$ and presence of $10 \mathrm{nM} \mathrm{E}_{2}\left(10 \mathrm{E}_{2}\right)$ for $24 \mathrm{~h}$ to analyze S/c2a 4 mRNA (A) and total cellular GLUT4 (B) contents. Representative immunoblots of GLUT4 and ACTB (loading control) are shown (B). Data are means \pm S.E.M. of 5-8 samples, analyzed by Mann-Whitney test (A) or unpaired Student $t$ test (B). $* * P<0.01$ and $* * * P<0.001$ vs $0 E_{2}$. For GLUT4

translocation analysis (C), cultivated cells were insulin stimulated (+) for $20 \mathrm{~min}$ or not (-). Immunofluorescence shows GLUT4 (red), nuclear marker DAPI (blue) and plasma membrane marker WGA (green). Merged images show the plasma membrane GLUT4 localization (yellow). Images are representative of at least 3 independent experiments. Scale bar is indicated.

absence or presence of $\mathrm{E}_{2}$, mimicking the $\mathrm{E}_{2}$ effect. Besides, Fig. 3E shows that MPP (ESR1-selective antagonist) abrogated the $\mathrm{E}_{2}$-induced plasma membrane translocation of ESR1. These results reveal that ESR1 redistribution was dependent on its own activity.

We also tested the involvement of SRC protein kinases in ESR1 translocation, from nucleus to plasma membrane (Fig. 3F), by concomitant treatment of the adipocytes with $\mathrm{E}_{2}$ and PP2, a selective inhibitor of SRC kinases. The addition of PP2 completely blocked the $\mathrm{E}_{2}$-induced ESR1 translocation, evincing the participation of SRC proteins in $\mathrm{E}_{2}$-induced ESR1 redistribution.

\section{Insulin causes no acute change in ESR1 translocation}

Twenty-minute insulin stimulation, at the end of the 24-h $\mathrm{E}_{2}$ treatment (Fig. 4A), did not alter the subcellular distribution of ESR1 caused by $\mathrm{E}_{2}$, nor the distribution caused by PPT (Fig. 4B), MPP (Fig. 4C) and PP2 (Fig. 4D), compared with the effects described in the absence of insulin (Fig. 3A, B, D, E and F; respectively).

Plasma membrane ESR1 translocation is accompanied by increased AKT activity

Some effects of plasma membrane-related ESR1 have been described as mediated by AKT, a key step in the insulin signaling pathway. Considering that, we evaluated AKT phosphorylation under conditions in which ESR1 is translocated from nucleus to plasma membrane. Figure $5 \mathrm{~A}$ shows that 24-h $10 \mathrm{nM} \mathrm{E}_{2}$ induced a $\sim 20$-fold increase in AKT phosphorylation $(P<0.05)$, pointing out the absence of insulin. Furthermore, in zero $\mathrm{E}_{2}$ and zero insulin, the

Published by Bioscientifica Ltd 

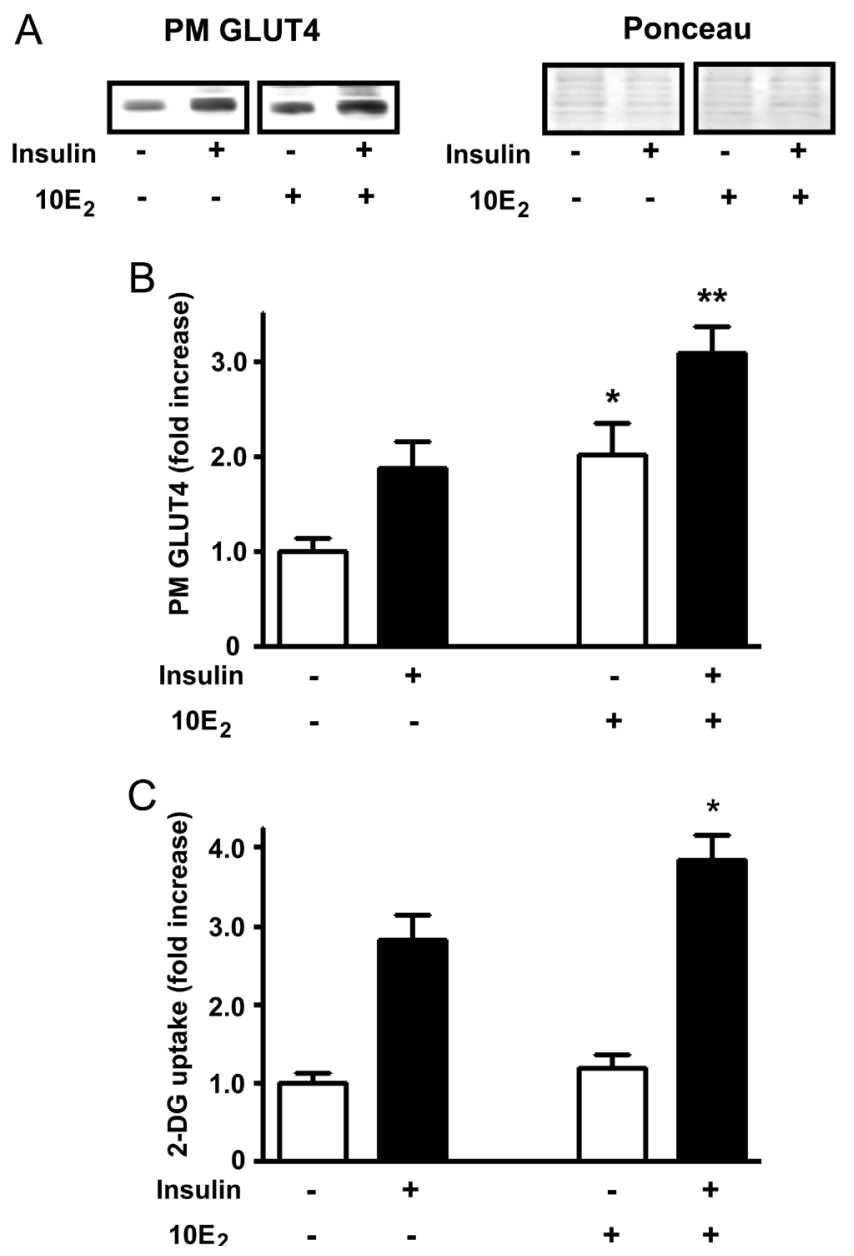

Figure 2

$E_{2}$ stimulates GLUT4 translocation and increases insulin-induced glucose uptake. Adipocytes were cultivated in the absence $\left(0 \mathrm{E}_{2}\right)$ and presence of $10 \mathrm{nM} \mathrm{E}_{2}\left(10 \mathrm{E}_{2}\right)$ for $24 \mathrm{~h}$, and additionally insulin stimulated (+) during the last 20 min or not (-). (A) Representative GLUT4 protein immunoblots in $\mathrm{PM}$ and respective loading control in the Ponceau-stained membrane. (B) PM GLUT4 translocation and (C) 2-deoxy-D-[3H]glucose (2-DG) uptake. Results are means \pm S.E.M. of 5 samples and were analyzed by two-way ANOVA: in (B), $P=0.0006$ for $E_{2}, P=0.0040$ for insulin and $P=0.6022$ for interaction and in (C), $P=0.0214$ for $E_{2}, P<0.0001$ for insulin, $P=0.1062$ for interaction. ${ }^{*} P<0.05$ and $* * P<0.01$ vs respective condition in $0 \mathrm{E}_{2}$ (Bonferroni post-test).

p-AKT content is very low, although clearly detected by optic densitometry; that is the reason why we considered $10 \mathrm{E}_{2}$ as 100 .

Additionally (Fig. 5B), we detected, always in the absence of insulin, that the ESR1-agonist PPT mimicked $10 \mathrm{E}_{2}$ effect and that the SRC kinases inhibitor PP2 completely blocked the $10 \mathrm{E}_{2}$ effect.

Once the effects of $\mathrm{E}_{2}$, PPT and PP2 on AKT phosphorylation in the absence of insulin were demonstrated, additional experiments were performed in the presence of insulin. $\mathrm{E}_{2}(10 \mathrm{nM})$ and PPT (Fig. 6A) sensitized the adipocytes to the insulin-stimulated AKT phosphorylation $\left(\mathrm{E}_{2}: \quad P<0.0001\right.$, two-way ANOVA); PPT: $P<0.001$ vs $0 \mathrm{E}_{2}$ ); besides, MPP abrogated the $\mathrm{E}_{2}$ induced effect $\left(P<0.001\right.$ vs $\left.10 \mathrm{E}_{2}\right)$. Finally, Fig. 6B shows that $E_{2}$-induced enhancement of insulin-stimulated AKT phosphorylation was also abrogated by PP2 $\left(P<0.001\right.$ vs $\left.10 \mathrm{E}_{2}\right)$.

\section{G protein-coupled estrogen receptor (GPER1) does not participate in the $E_{2}$-induced activation of AKT}

To check the probable participation of GPER1 in the $\mathrm{E}_{2}$ sensitizer effect of insulin-stimulated activation of AKT, we treated the cells with $10 \mathrm{E}_{2}$ plus G15, an inhibitor of GPER1. Figure 7 shows that G15 did not alter the $\mathrm{E}_{2}$ activation of AKT, indicating that the $\mathrm{E}_{2}$ effect occurs independently of GPER1.

\section{Discussion}

Estrogen is reported to participate in the glycemic homeostasis, and $\mathrm{E}_{2}$-induced modulation of cellular glucose disposal has been proposed since the beginning of years 2000 (Barros et al. 2006a). Recently, in MCF-7 cells, a rapid ( $25 \mathrm{~min}$ ) enhancing effect of $\mathrm{E}_{2}$ upon glucose uptake was reported and suggested to be related to the plasma membrane ESR1 localization (Garrido et al. 2013). Here, we unravel a plasma membrane ESR1-related $\mathrm{E}_{2}$ stimulation of glucose uptake, in a classic insulinsensitive cell.

We observed that Esr1 mRNA expression is higher than Esr2 mRNA expression in differentiated 3T3-L1 adipocyte; similar to that described in differentiated human adipocytes (Dieudonné et al. 2004). The Esr1>Esr2 mRNA expression, analyzed by quantitative real-time PCR, offers accurate data, which allow us to suggest that ESR1 protein is also more abundant than ESR2 protein. However, that cannot be confirmed, since the effectiveness of different antibodies (anti-ESR1 vs anti-ESR2) is unmatched.

An important issue is the hypothetical effect of $E_{2}$ upon ESR1/ESR2 expression. Human adipocytes, subjected to 24-h culture with $100 \mathrm{nM} \mathrm{E}_{2}$, alter ESR1/ESR2 mRNA expression according to the adipose depot (subcutaneous or intra-abdominal) and to the gender (male or female); however, the respective proteins were not evaluated (Dieudonné et al. 2004). In previous study, we reported that ESR1 and ESR2 protein contents do not change in response to 24-h $10 \mathrm{nM} \mathrm{E}_{2}$ (Campello et al. 2012a); thus, it becomes clear that $\mathrm{E}_{2}$ acts in 3T3-L1 adipocytes mainly 
A
DAPI
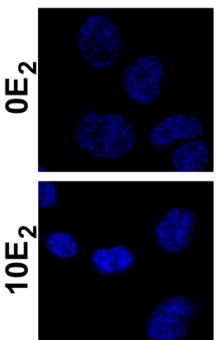

ESR1
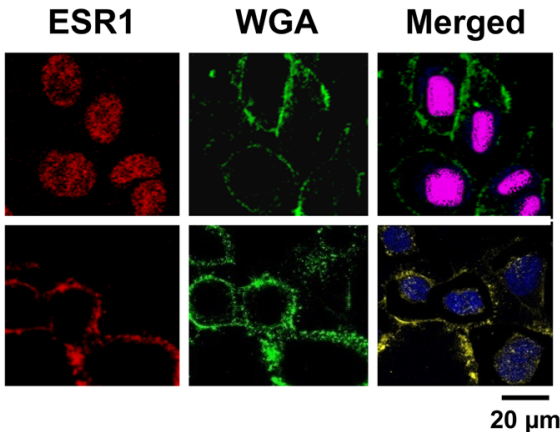

C

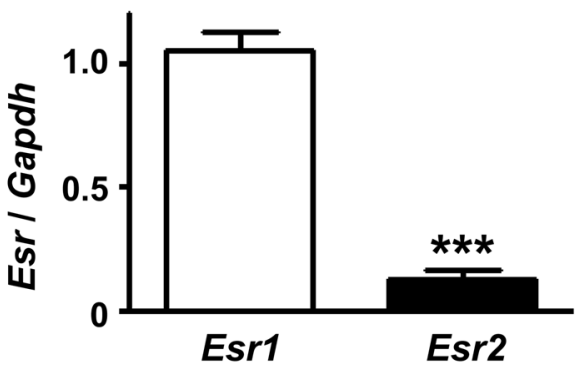

E
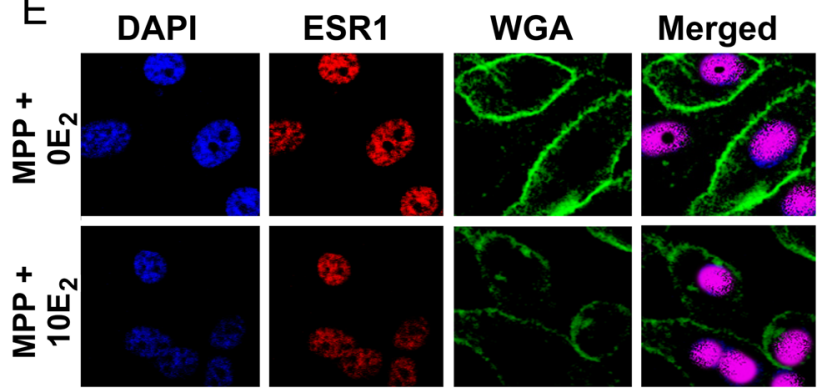

B
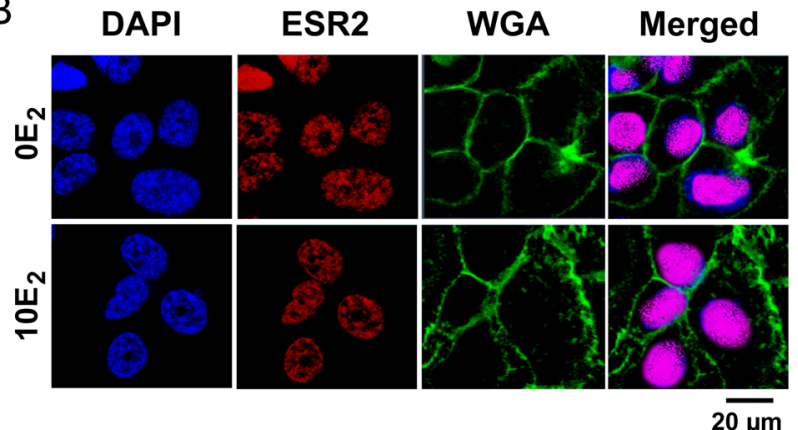

D
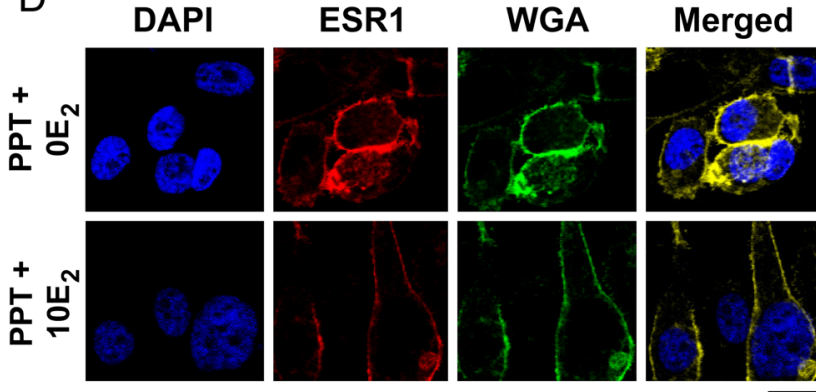

$\mathrm{F}$
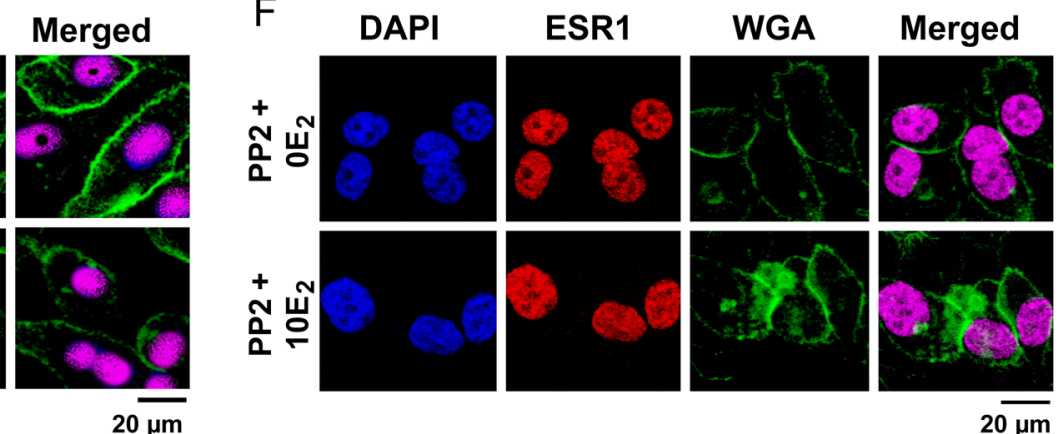

Figure 3

Subcellular distribution and gene expression of ESR1 and ESR2. Panels (A) and (B) show the subcellular localization of ESR1 and ESR2; respectively, in adipocytes cultivated in absence $\left(0 \mathrm{E}_{2}\right)$ or presence of $10 \mathrm{nM} \mathrm{E} \mathrm{E}_{2}(10 \mathrm{E} 2)$ for $24 \mathrm{~h}$. Relative expression (C) of Esr1 and Esr2 mRNAs was analyzed using Gapdh gene as internal control; $* * * P<00.0001$. Subcellular localization of ESR1 in adipocytes is also shown in adipocytes treated with ESR1-agonist PPT (D), ESR1-antagonist MPP (E) or SRC inhibitor PP2 (F), in the absence (0E2) or presence of $10 \mathrm{nM}$ E2 (10E2), for 24h. Immunofluorescence shows ESR1 and ESR2 (red), nuclear marker DAPI (blue) and plasma membrane marker WGA (green). Merged images show the nuclear localization of ESR1 and ESR2 (magenta), and the plasma membrane localization of ESR1 (yellow). Images are representative of at least 3 independent experiments. Scale bars (20 $\mu$ m) are indicated.

via ESR1, involving ESR1 subcellular redistribution. Nevertheless, the present results, obtained in a cell line originated from a mouse embryo, must be carefully transposed to humans.

The main biological effects of $\mathrm{E}_{2}$ are mediated by ESRs; however, in addition to their classical nuclear action, recent studies have shown that ESRs also act outside the nucleus (Gutiérrez et al. 2012). ESR1 and ESR2 translocation to plasma membrane was described as a rapid 10- to 15-min response (Lucas et al. 2008,
Bondar et al. 2009, Gutiérrez et al. 2012). In 3T3-L1 adipocytes, plasma membrane translocation of ESR1 was observed after 16-h $\mathrm{E}_{2}$ treatment (Nagira et al. 2006), but with a hormone concentration one thousand higher than that used in the present study. For the first time, we show a remarkable $\mathrm{E}_{2}$-induced selective ESR1 shuttle from nucleus to plasma membrane, after a 24-h treatment with $10 \mathrm{nM} \mathrm{E}_{2}$; an effect that was mimicked by PPT (ESR1 agonist) and abrogated by MPP (ESR1 antagonist). These data reveal that the activation of

Published by Bioscientifica Ltd 
A
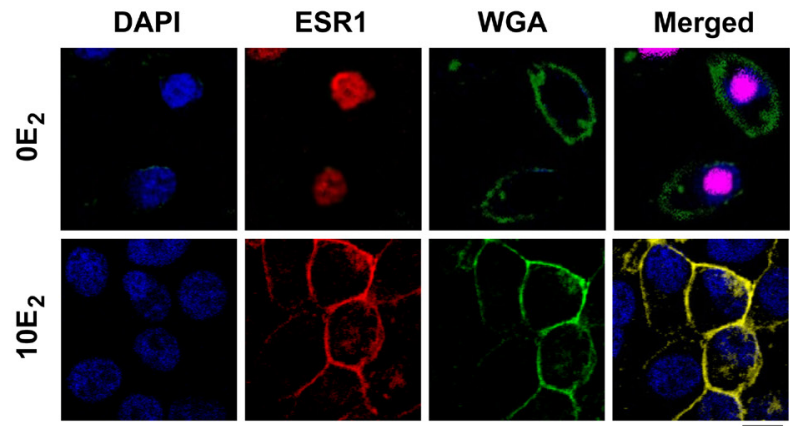

B
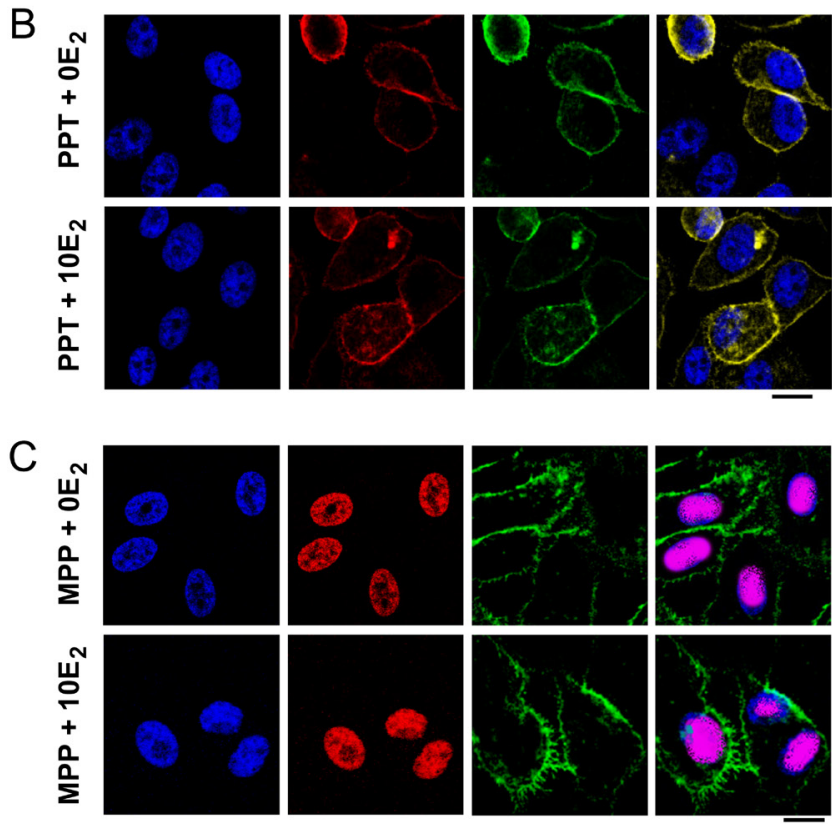

D
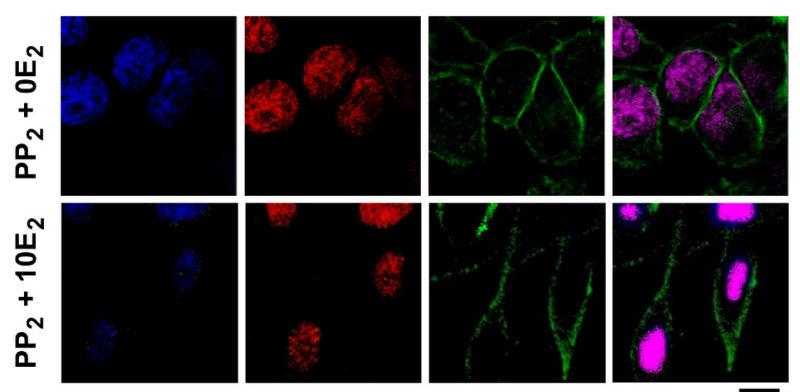

$20 \mu \mathrm{m}$

Figure 4

Insulin stimulation did not alter redistribution of ESR1. Subcellular localization of ESR1 in $3 T 3 \mathrm{~L} 1$ adipocytes $24 \mathrm{~h}$ treated with zero $\left(0 \mathrm{E}_{2}\right)$ or 10 (10E2) nM 17 -estradiol (A), $\mathrm{OE}_{2}$ and $10 \mathrm{E}_{2}+\mathrm{SR} 1$ agonist PPT (B), $\mathrm{OE}_{2}$ and $10 \mathrm{E} 2+\mathrm{ESR} 1$ antagonist MPP (C); $0 \mathrm{E}_{2}$ and $10 \mathrm{E}_{2}+\mathrm{SRC}$ antagonist PP2 (D). Under all conditions, the cells were stimulated with insulin $(20 \mathrm{~min})$ at the end of the $24 \mathrm{~h}$ treatment. Images show immunofluorescence of ESR1 (red), nuclear marker DAPI (blue) and plasma membrane marker WGA (green). Merged images show ESR1 localization in nucleus (magenta) or in plasma membrane (yellow). Images are representative of at least 3 independent experiments. Scale bars $(20 \mu \mathrm{m})$ are indicated.
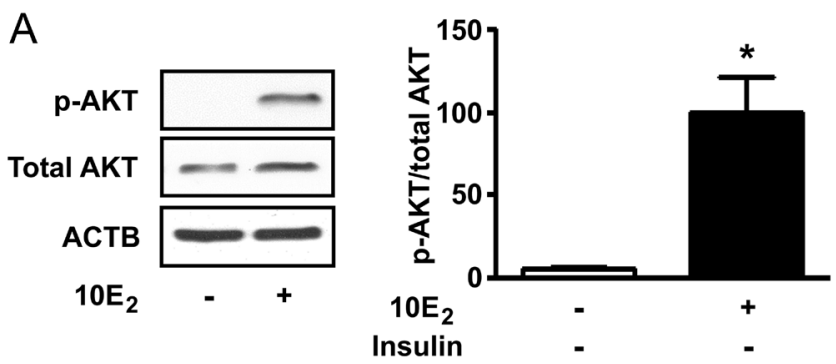

B

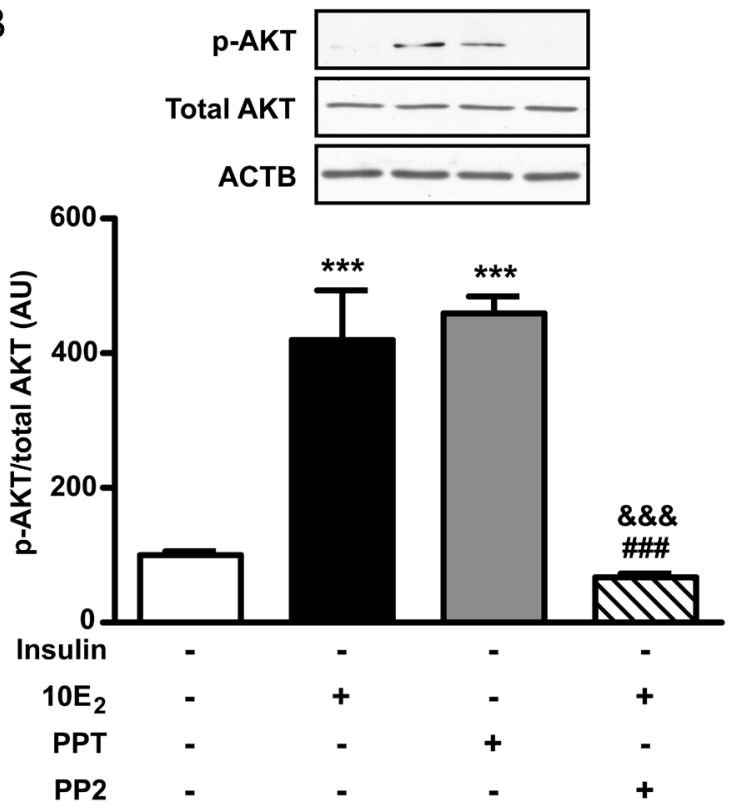

Figure 5

Plasma membrane ESR1 translocation is accompanied by increased AKT activity. Adipocytes were cultivated in absence of $10 \mathrm{nM} \mathrm{E}_{2}\left(0 \mathrm{E}_{2}\right)$, or in the presence of $E_{2}\left(10 E_{2}\right)$, ESR1-selective agonist (PPT), or $10 E_{2}$ plus SRC antagonist (10E $\left.E_{2}+P P 2\right)$, and not stimulated with insulin. In (A), 10E effect was investigated separately, whereas in (B), it was compared to PPT and PP2 effects. In each panel, representative images of p-AKT, total AKT and ACTB are shown. Results of $p$-AKT were normalized by ACTB as loading control, and thus by the results of total AKT. Results are means \pm s.E.M. of 4 (A) and 5 (B) samples. Data were analyzed by Mann-Whitney test in (A), ${ }^{*} P<0.05$; and by one-way ANOVA, followed by Newman-Keuls post-test, in (B): $* * * P<0.001$ vs $0 \mathrm{E}_{2},{ }^{*} \# \# P<0.01$ vs $10 \mathrm{E}_{2}$ and $\& \& \& P<0.01$ vs PPT.

ESR1 is necessary for its own subcellular redistribution in 3T3-L1 adipocytes.

The SRC tyrosine kinases present several functional domains. When the Tyr 530 in the C-terminus is dephosphorylated, the kinase activity is triggered, and the protein interacts with target proteins (Chojnacka \& Mruk 2015). ESR1-Tyr537 phosphorylation induces its molecular interaction with SRC protein (Nieto et al. 2015), leading to SRC activation (Barletta et al. 2004); on the other hand, ESR1-Tyr537 phosphorylation has been http://jme.endocrinology-journals.org DOI: 10.1530/JME-17-0041
C 2017 Society for Endocrinology Printed in Great Britain 
A

B
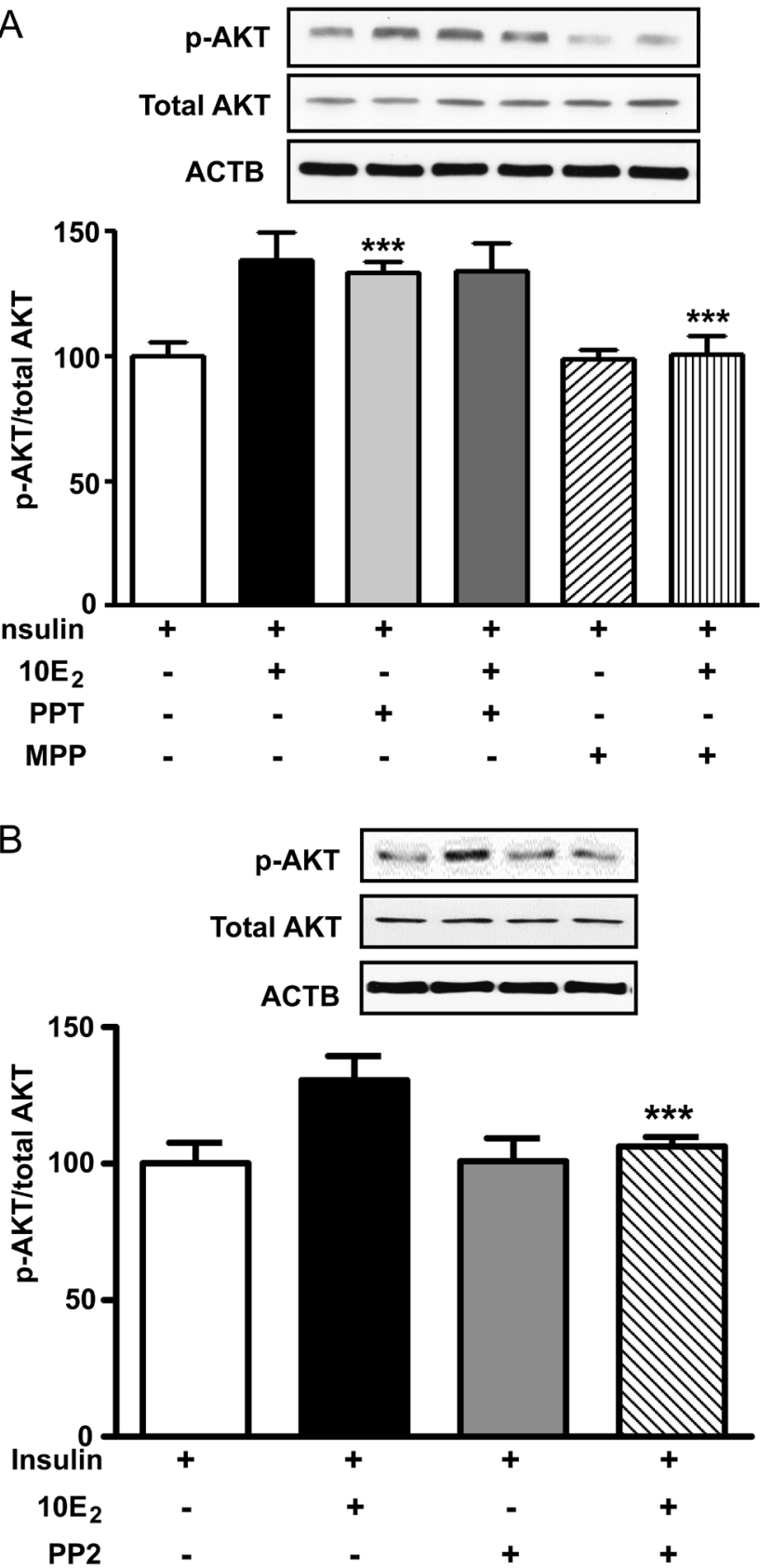

Figure 6

Plasma membrane ESR1 translocation sensitizes insulin-induced AKT activation. Adipocytes were cultivated in absence (OE2) or in presence of $10 \mathrm{nM} \mathrm{E}_{2}\left(10 \mathrm{E}_{2}\right)$, and additionally treated or not with ESR 1 agonist (PPT) and ESR1 antagonist (MPP), panel (A), or with SRC antagonist (PP2), panel (B). Under all conditions, the cells were stimulated with insulin (20 min) at the end of the 24-h treatment. In each panel, representative images of $\mathrm{p}-\mathrm{AKT}$, total AKT and ACTB are shown. Results of $\mathrm{p}-\mathrm{AKT}$ were normalized by ACTB as loading control, and thus by the results of total AKT. Results are means \pm S.E.M. of 5-8 (A) or 5 samples (B). Data were analyzed by two-way ANOVA: $P<0.0001$ for $\mathrm{E}_{2}, P<0.01$ for treatments (PPT, MPP and PP2) and $P<0.01$ for interaction, $* * * P<0.001$ vs respective untreated condition (Bonferroni post-test).

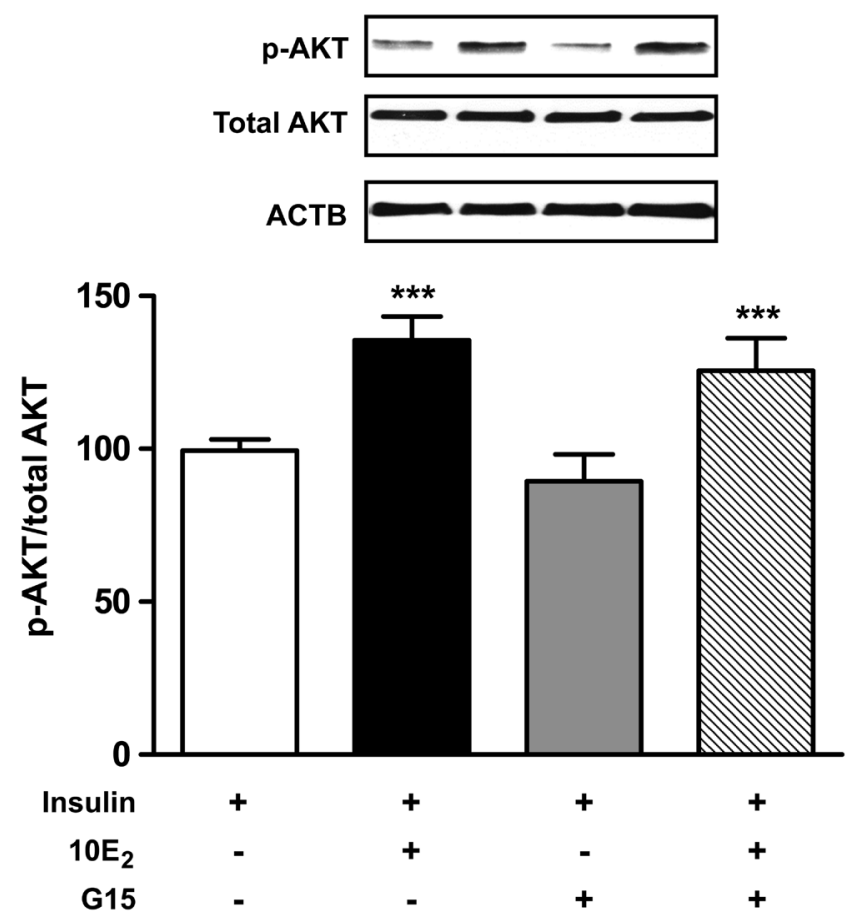

Figure 7

$E_{2}$ sensitization of insulin-induced activation of AKT is not mediated by GPER1. Adipocytes were cultivated in the absence $\left(0 E_{2}\right)$ or in presence of $10 \mathrm{nM} \mathrm{E}_{2}\left(10 \mathrm{E}_{2}\right)$ and treated or not with GPER1 antagonist (G15).

Additionally, the cells were stimulated with insulin $(20 \mathrm{~min})$ at the end of the 24-h treatment. Representative images of p-AKT, total AKT and ACTB are shown. Results of p-AKT were normalized by ACTB as loading control, and thus, by the results of total AKT. Results are means \pm S.E.M. of 6 samples and were analyzed by two-way ANOVA: $P<0.0001$ for $E_{2}$, $* * * P<0.001$ vs respective $0 \mathrm{E}_{2}$ (Bonferroni post-test).

proposed to occur in response to SRC activation, leading to nuclear shuttle of the receptor (Castoria et al. 2012). In fact, in Sertoli cells, 10-min $\mathrm{E}_{2}$ induces a SRC-mediated translocation of both ESR1 and ESR2 to plasma membrane (Lucas et al. 2008). Our results in adipocytes revealed that the SRC inhibitor (PP2) blocked the 24-h $\mathrm{E}_{2}$-induced ESR1 translocation from nucleus to membrane, confirming the participation of SRC proteins in the ESR1 mobilization.

$\mathrm{E}_{2}$-induced activation of PI3K/AKT was clearly reported to occur via ESR1 in MCF-7 cells (Lee et al. 2005). In 3T3L1 adipocytes, $100 \mathrm{nM} \mathrm{E}_{2}$ (high concentration) rapidly activates IRS1 and AKT, but the participation of ESR1 or ESR2 was not investigated (Kim et al. 2012). Regarding that, plasma membrane-related ESR1 was reported to bind and activate PI3K in endothelial cells (Simoncini et al. 2000), thus explaining AKT activation, which could enhance the insulin effect on this pathway. In fact, $10 \mathrm{nM} \mathrm{E}_{2}$ enhanced the insulin-stimulated activation of AKT and glucose uptake in adipocytes; however, that

Published by Bioscientifica Ltd. http://jme.endocrinology-journals.org DOI: 10.1530/JME-17-0041
○ 2017 Society for Endocrinology Printed in Great Britain 
was inexplicably related to low plasma membrane and high nuclear contents of ESR1 (Nagira et al. 2006). Those studies together do not provide a clear comprehension of $\mathrm{E}_{2}$-induced plasma membrane translocation of ESR1, AKT activation and cellular glucose disposal improvement.

To unravel those $\mathrm{E}_{2}$-induced effects, we firstly investigated the AKT activation in the absence of insulin, seeking to relate the results to the plasma membrane ESR1 localization. We demonstrated that $10 \mathrm{nM} \mathrm{E}_{2}$ induced a strong increase in AKT phosphorylation, an effect that was mimicked by PPT and abrogated by PP2. These data together relate the AKT activation to the plasma membrane ERS1 localization.

Besides, $\mathrm{E}_{2}$ was also analyzed as a sensitizer of insulininduced stimulation of AKT, since, in vivo, insulin plays a fundamental role in AKT activity. $\mathrm{E}_{2}$ and PPT increased the insulin-stimulated AKT phosphorylation, and the $\mathrm{E}_{2}$ effect was blocked by MPP or PP2. These data disclose $E_{2}$ as a sensitizer of the insulin-stimulated activation of AKT and relate the $\mathrm{E}_{2}$ effect to the plasma membrane ESR1 translocation.

Finally, considering that $\mathrm{E}_{2}$ also triggers GPER1 activation, and that this receptor might also activate AKT, we tested the effect of GPER1 inhibitor G15. The results showed that G15 did not alter the $\mathrm{E}_{2}$ sensitizer effect on insulin-stimulated AKT phosphorylation. In fact, participation of GPER1 in the $\mathrm{E}_{2}$-induced activation of AKT is variable, according to the cell type (Vivacqua et al. 2006, Carnesecchi et al. 2015). In summary, the absence of G15 effect reinforces the relationship between plasma membrane ESR1 and AKT activation.

AKT plays a fundamental role in glucose uptake in insulin-sensitive tissues, participating in the insulinstimulated translocation of GLUT4 storage vesicles (GSV) from the intracellular to the plasma membrane (Kohn et al. 1996). On the other hand, it is known that increased plasma membrane GLUT4 content naturally accompanies increased Slc2a4/GLUT4 expression, as demonstrated in transgenic mice that overexpress GLUT4 (Gibbs et al. 1995). In the present study, ESR1-mediated $\mathrm{E}_{2}$ effect increased PM GLUT4 content by AKT-mediated GSV translocation. Besides, $\mathrm{E}_{2}$ increased the Slc2a4/GLUT4 expression, which additionally contributes to increase PM GLUT4, and also seems to be related to ESR1, since ESR1 activity increases, whereas ESR2 activity decreases Slc2a4/ GLUT4 expression (Campello et al. 2012a).

The $\mathrm{E}_{2}$-stimulated Slc2a4 expression has been proposed as an ESR1-mediated genomic effect on the promoter region of Slc2a4 gene, in which the repression of NFKB could participate (Barros et al. 2006a). Now, the present data depict that $\mathrm{E}_{2}$ induces a strong nuclear shuttle of ESR1, indicating that the enhancement of Slc2a4 expression could be triggered outside the nucleus, despite involving the NFKB pathway. To support this hypothesis, we point out that: (1) AKT activation inhibits NFKB activity (Ruan et al. 2002), (2) NFKB is a powerful repressor of Slc2a4 transcription (Furuya et al. 2013) and (3) insulin-induced activation of AKT reduces NFKB-mediated repression of Slc2a4 transcription (Moraes et al. 2014). Furthermore, in 3T3-L1 adipocytes, we had already reported that 24-h PPT treatment reduces NFKB binding to Slc2a4 gene, enhancing Slc2a4/GLUT4 expression (Campello et al. $2012 a$ ), which now became clear to be triggered by the plasma membrane-related ESR1. Additionally, the present study confirmed an ESR1-mediated $\mathrm{E}_{2}$ effect upon glucose uptake in adipocytes; however, for the first time, this effect is clearly related to the plasma membrane localization of ESR1, AKT activation and GLUT4 translocation under the same experimental protocol.

An unexpected result was observed in response to $\mathrm{E}_{2}$ in the absence of insulin: despite the increased PM GLUT4 translocation, the glucose uptake did not increase. It has been proposed that in addition to AKT-dependent phosphorylation of AS160, insulin-induced activation of some plasma membrane- and actin remodeling-related proteins is also required for GSV docking and fusion to the cell surface (Koumanov et al. 2005, Bai et al. 2007). Thus, we can propose that $\mathrm{E}_{2}$ induces the translocation of GSV to the plasma membrane, but the GSV docking and/or fusion are not achieved in the absence of insulin, preventing the increase in basal glucose uptake.

A growing body of evidence indicates a relationship between $\mathrm{E}_{2}$ and glycemic homeostasis in vivo. In this regard, $\mathrm{E}_{2}$ treatment has been shown to restore the glucose uptake in oophorectomized rats (Kumagai et al. 1993) and to maintain the insulin sensitivity in postmenopausal women (Moreno et al. 2010). In the present study, we provide evidence that $24-\mathrm{h}_{2}$ treatment of 3T3-L1 adipocytes induces a SRC-mediated nucleusplasma membrane shuttle of ESR1, which is accompanied by increased phosphorylation of AKT, and increased Slc2a4/GLUT4 expression and plasma membrane GLUT4 translocation; consequently, improving insulin-stimulated glucose uptake. These results unravel mechanisms through which estrogen contributes to improve insulin sensitivity, highlighting that this effect is mediated by ESR1.

Declaration of interest

The authors declare that there is no conflict of interest that could be perceived as prejudicing the impartiality of the research reported.

Published by Bioscientifica Ltd. 


\section{Funding}

This research was supported by FAPESP (São Paulo State Foundation for Research) grants 2012/24210-1, 2012/04831-1 and 2016/15603-1.

\section{Acknowledgment}

The authors thank Dr Adauri Brezolin for revision of the English language of this manuscript.

\section{References}

Acconcia F, Ascenzi P, Bocedi A, Spisni E, Tomasi V, Trentalance A, Visca P \& Marino M 2005 Palmitoylation-dependent estrogen receptor alpha membrane localization: regulation by 17 betaestradiol. Molecular Biology of the Cell 16 231-237. (doi:10.1091/mbc. E04-07-0547)

Adlanmerini M, Solinhac R, Abot A, Fabre A, Raymond-Letron I, Guilhot AL, Boudou F, Sautier L, Vessières E \& Kim SH 2014 Mutation of the palmitoylation site of estrogen receptor $\alpha$ in vivo reveals tissuespecific roles for membrane versus nuclear actions. PNAS 111 $\mathrm{E}_{2} 83-\mathrm{E}_{2}$ 90. (doi:10.1073/pnas.1322057111)

Bai L, Wang Y, Fan J, Chen Y, Ji W, Qu A, Xu P, James DE \& Xu T 2007 Dissecting multiple steps of GLUT4 trafficking and identifying the sites of insulin action. Cell Metabolism 5 47-57. (doi:10.1016/j. cmet.2006.11.013)

Barletta F, Wong CW, Mcnally C, Komm BS, Katzenellenbogen B \& Cheskis BJ 2004 Characterization of the interactions of estrogen receptor and MNAR in the activation of cSrc. Molecular Endocrinology 18 1096-1108. (doi:10.1210/me.2003-0335)

Barros RP, Machado UF \& Gustafsson JA 2006a Estrogen receptors: new players in diabetes mellitus. Trends in Molecular Medicine 12 425-431. (doi:10.1016/j.molmed.2006.07.004)

Barros RP, Machado UF, Warner M \& Gustafsson JA 2006b Muscle GLUT4 regulation by estrogen receptors ERbeta and ERalpha. PNAS 103 1605-1608. (doi:10.1073/pnas.0510391103)

Barros RP, Morani A, Moriscot A \& Machado UF 2008 Insulin resistance of pregnancy involves estrogen-induced repression of muscle GLUT4. Molecular and Cellular Endocrinology 295 24-31. (doi:10.1016/j. mce.2008.07.008)

Barros RP, Gabbi C, Morani A, Warner M \& Gustafsson JA 2009 Participation of ERalpha and ERbeta in glucose homeostasis in skeletal muscle and white adipose tissue. American Journal of Physiology: Endocrinology and Metabolism 297 124-133. (doi:10.1152/ ajpendo.00189.2009)

Bondar G, Kuo J, Hamid N \& Micevych P 2009 Estradiol-induced estrogen receptor-alpha trafficking. Journal of Neuroscience $\mathbf{2 9}$ 15323-15330. (doi:10.1523/JNEUROSCI.2107-09.2009)

Björnholm M \& Zierath JR 2005 Insulin signal transduction in human skeletal muscle: identifying the defects in Type II diabetes. Biochemical Society Transactions 33 354-357. (doi:10.1042/bst0330354)

Campello RS, Alves-Wagner AB, Lucas TF, Mori RC, Furuya DT, Porto CS \& Machado UF 2012a Estrogen receptor 1 agonist PPT stimulates Slc2a4 gene expression and improves insulin-induced glucose uptake in adipocytes. Current Topics in Medicinal Chemistry 12 2059-2069. (doi:10.2174/156802612804910197)

Campello RS, Alves-Wagner AB, Abdulkader F, Mori RC \& Machado UF $2012 b$ Carbohydrate- and lipid-enriched meals acutely disrupt glycemic homeostasis by inducing transient insulin resistance in rats. Canadian Journal of Physiology and Pharmacology 90 537-545. (doi:10.1139/y2012-056)

Carnesecchi J, Malbouyres M, de Mets R, Balland M, Beauchef G, Vié K, Chamot C, Lionnet C, Ruggiero F \& Vanacker JM 2015 Estrogens induce rapid cytoskeleton re-organization in human dermal fibroblastos via the non-classical receptor GPR30. PLoS ONE 10 e0120672. (doi:10.1371/journal.pone.0120672)

Castoria G, Giovannelli P, Lombardi M, De Rosa C, Giraldi T, de Falco A, Barone MV, Abbondanza C, Miggliaccio A \& Auricchio F 2012 Tyrosine phosphorylation of estradiol receptor by Src regulates its hormone-dependent nuclear export and cell cycle progression in breast cancer cells. Oncogene 31 4868-4877. (doi:10.1038/ onc.2011.642)

Chojnacka K \& Mruk DD 2015 The Src non-receptor tyrosine kinase paradigm: new insights into mammalian Sertoli cell biology. Molecular and Cellular Endocrinology 415 133-142. (doi:10.1016/j. mce.2015.08.012)

Collison M, Campbell IW, Salt IP, Dominiczak AF, Connell JM, Lyall H \& Gould GW 2000 Sex hormones induce insulin resistance in 3T3-L1 adipocytes by reducing cellular content of IRS proteins. Diabetologia 43 1374-1380. (doi:10.1007/s001250051541)

Corrêa-Giannella ML \& Machado UF 2013 SLC2A4gene: a promising target for pharmacogenomics of insulin resistance. Pharmacogenomics 14 847-850. (doi:10.2217/pgs.13.45)

Dauvois S, White R \& Parker MG 1993 The antiestrogen ICI 182780 disrupts estrogen receptor nucleocytoplasmic shuttling. Journal of Cell Science 106 1377-1388.

De Castro Barbosa T, Jiang LQ, Zierath JR \& Nunes MT 2013 L-Arginine enhances glucose and lipid metabolism in rat L6 myotubes via the NO/c-GMP pathway. Metabolism 62 79-89. (doi:10.1016/j. metabol.2012.06.011)

Dieudonné MN, Leneveu MC, Giudicelli Y, Pecquery R 2004 Evidence for functional estrogen receptors alpha and beta in human adipose cells: regional specificities and regulation by estrogens. American Journal Physiology: Cell Physiology 286 C655-C661. (doi:10.1152/ ajpcell.00321.2003)

Faustini-Fustini M, Rochira V \& Carani C 1999 Oestrogen deficiency in men: where are we today? European Journal of Endocrinology $\mathbf{1 4 0}$ 111-129. (doi:10.1530/eje.0.1400111)

Furuya DT, Neri EA, Poletto AC, Anhê GF, Freitas HS, Campello RS, Rebouças NA \& Machado UF 2013 Identification of nuclear factor-kB sites in the Slc2a4 gene promoter. Molecular and Cellular Endocrinology 370 87-95. (doi:10.1016/j.mce.2013.01.019)

Galien R \& Garcia T 1997 Estrogen receptor impairs interleukin-6 expression by preventing protein binding on the NF-kappaB site. Nucleic Acids Research 25 2424-2429. (doi:10.1093/nar/25.12.2424)

Garrido P, Morán J, Alonso A, González S \& González C 2013 $17 \beta$-estradiol activates glucose uptake via GLUT4 translocation and PI3K/Akt signaling pathway in MCF-7 cells. Endocrinology $\mathbf{1 5 4}$ 1979-1989. (doi:10.1210/en.2012-1558)

Gibbs EM, Stock JL, Mccoid SC, Stukenbrok HA, Pessin JE, Stevenson RW, Millici AJ \& McNeish JD 1995 Glycemic improvement in diabetic $\mathrm{db} / \mathrm{db}$ mice by overexpression of the human insulin-regulatable glucose transporter (GLUT4). Journal of Clinical Investigation 95 1512-1518. (doi:10.1172/JCI117823)

Gutiérrez S, Sosa LD, Petiti JP, Mukdsi JH, Mascanfroni ID, Pellizas CG, De Paul AL, Cambiasso MJ \& Torres AI 2012 17ß-Estradiol stimulates the translocation of endogenous estrogen receptor $\alpha$ at the plasma membrane of normal anterior pituitary cells. Molecular and Cellular Endocrinology 355 169-179. (doi:10.1016/j. mce.2012.02.008)

Heldring N, Pike A, Andersson S, Matthews J, Cheng G, Hartman J, Tujague M, Ström A, Treuter E, Warner M, et al. 2007 Estrogen receptors: how do they signal and what are their targets. Physiological Reviews 87 905-931. (doi:10.1152/physrev.00026.2006)

Kang L, Zhang X, Xie Y, Tu Y, Wang D, Liu Z \& Wang ZY 2010 Involvement of estrogen receptor variant ER-alpha36, not GPR30, in nongenomic estrogen signaling. Molecular Endocrinology 24 709-721. (doi:10.1210/me.2009-0317)

Kim JY, Jo KJ, Kim BJ, Baik HW \& Lee SK 2012 17ß-estradiol induces an interaction between adenosine monophosphate-activated protein

Published by Bioscientifica Ltd 
kinase and the insulin signaling pathway in 3T3-L1 adipocytes. International Journal of Molecular Medicine 30 979-985.

Kohn AD, Summers SA, Birnbaum MJ \& Roth RA 1996 Expression of a constitutively active Akt Ser/Thr kinase in 3T3-L1 adipocytes stimulates glucose uptake and glucose transporter 4 translocation. Journal of Biological Chemistry 271 31372-31378. (doi:10.1074/ jbc.271.49.31372)

Konigame VC, Siu ER, Royer C, Lucas TF, Porto CS \& Abdalla FM 2011 Estrogen receptors mediate rapid activation of phospholipase C pathway in the rat endometrium. Steroids 76 1582-1589. (doi:10.1016/j.steroids.2011.09.013)

Koumanov F, Jin B, Yang J \& Holman GD 2005 Insulin signaling meets vesicle traffic of GLUT4 at a plasma-membrane-activated fusion step. Cell Metabolism 2 179-189. (doi:10.1016/j.cmet.2005.08.007)

Krishnan V, Wang X \& Safe S 1994 Estrogen receptor-Sp1 complexes mediate estrogen-induced cathepsin D gene expression in MCF-7 human breast cancer cells. Journal of Biological Chemistry 269 15912-15917.

Kumagai S, Holmäng A \& Björntorp P 1993 The effects of oestrogen and progesterone on insulin sensitivity in female rats. Acta Physiologica Scandinavica 149 91-97. (doi:10.1111/j.1748-1716.1993.tb09596.x)

Lee YR, Park J, Yu HN, Kim JS, Youn HJ \& Jung SH 2005 Up-regulation of PI3K/Akt signaling by 17beta-estradiol through activation of estrogen receptor-alpha, but not estrogen receptor-beta, and stimulates cell growth in breast cancer cells. Biochemical and Biophysical Research Communications 336 1221-1226. (doi:10.1016/j. bbrc.2005.08.256)

Levin ER 2014 Translating extranuclear steroid receptor signaling to clinical medicine. Hormones and Cancer 5 140-145. (doi:10.1007/ s12672-014-0179-9)

Lucas TF, Siu ER, Esteves CA, Monteiro HP, Oliveira CA, Porto CS \& Lazari MF 2008 17beta-estradiol induces the translocation of the estrogen receptors ESR1 and ESR2 to the cell membrane, MAPK3/1 phosphorylation and proliferation of cultured immature rat Sertoli cells. Biology of Reproduction 78 101-114. (doi:10.1095/ biolreprod.107.063909)

Meyer MR, Clegg DJ, Prossnitz ER \& Barton M 2011 Obesity, insulin resistance and diabetes: sex differences and role of oestrogen receptors. Acta Physiologica 203 259-269. (doi:10.1111/j.17481716.2010.02237.x)

Moraes PA, Yonamine CY, Pinto Junior DC, Esteves JV, Machado UF \& Mori RC 2014 Insulin acutely triggers transcription of Slc2a4 gene: participation of the AT-rich, E-box and NFKB-binding sites. Life Sciences 114 36-44. (doi:10.1016/j.lfs.2014.07.040)

Moreno M, Ordoñez P, Alonso A, Díaz F, Tolivia J \& González C 2010 Chronic 17beta-estradiol treatment improves skeletal muscle insulin signaling pathway components in insulin resistance associated with aging. Age 32 1-13. (doi:10.1007/s11357-009-9095-2)

Muraki K, Okuya S \& Tanizawa Y 2006 Estrogen receptor alpha regulates insulin sensitivity through IRS-1 tyrosine phosphorylation in mature
3T3-L1 adipocytes. Endocrine Journal 53 841-851. (doi:10.1507/ endocrj.K06-005)

Nagira K, Sasaoka T, Wada T, Fukui K, Ikubo M, Hori S, Tsuneki H, Saito S \& Kobayashi M 2006 Altered subcellular distribution of estrogen receptor alpha is implicated in estradiol-induced dual regulation of insulin signaling in 3T3-L1 adipocytes. Endocrinology 147 1020-1028. (doi:10.1210/en.2005-0825)

Nieto L, Tharun IM, Balk M, Wienk H, Boelens R, Ottmann C, Milroy LG \& Brunsveld L 2015 Estrogen receptor folding modulates cSrc kinase SH2 interaction via a helical binding mode ACS. Chemistry and Biology 10 2624-2632. (doi:10.1021/acschembio.5b00568)

Nilsson S \& Gustafsson JA 2011 Estrogen receptors: therapies targeted to receptor subtypes. Clinical Pharmacology and Therapeutics 89 44-55. (doi:10.1038/clpt.2010.226)

Prossnitz ER \& Barton M 2014 Estrogen biology: new insights into GPER function and clinical opportunities. Molecular and Cellular Endocrinology 389 71-83. (doi:10.1016/j.mce.2014.02.002)

Romero-Calvo I, Ocón B, Martínez-Moya P, Suárez MD, Zarzuelo A, Martinez-Augustin O \& de Medina FS 2010 Reversible ponceau staining as a loading control alternative to actin in Western blots. Analytical Biochemistry 401 318-320. (doi:10.1016/j.ab.2010.02.036)

Ruan H, Hacohen N, Golub TR, Van Parijs L \& Lodish HF 2002 Tumor necrosis factor-alpha suppresses adipocyte-specific genes and activates expression of preadipocyte genes in 3T3-L1 adipocytes: nuclear factor-kappaB activation by TNF-alpha is obligatory. Diabetes 51 1319-1336. (doi:10.2337/diabetes.51.5.1319)

Simoncini T, Hafezi-Moghadam A, Brazil DP, Ley K, Chin WW \& Liao JK 2000 Interaction of oestrogen receptor with the regulatory subunit of phosphatidylinositol-3-OH kinase. Nature $\mathbf{4 0 7} 538-541$. (doi:10.1038/35035131)

Smith EP, Boyd J, Frank GR, Takahashi H, Cohen RM, Specker B, Williams TC, Lubahn DB \& Korach KS 1994 Estrogen resistance caused by a mutation in the estrogen-receptor gene in a man. New England Journal of Medicine 331 1056-1061. (doi:10.1056/ NEJM199410203311604)

Solomon CG, Hu FB, Dunaif A, Rich-Edwards J, Willet WC, Hunter DJ, Colditz GA, Speizer FE \& Manson JE 2001 Long or highly irregular menstrual cycles as a marker for risk of type 2 diabetes mellitus. JAMA 286 2421-2426. (doi:10.1001/jama.286.19.2421)

Tsuchiya A, Kanno T \& Nishizaki T 2013 PI3 kinase directly phosphorylates Akt1/2 at Ser473/474 in the insulin signal transduction pathway. Journal of Endocrinology 220 49-59. (doi:10.1530/JOE-13-0172)

Vivacqua A, Bonofiglio D, Recchia AG, Musti AM, Picard D, Andò S \& Maggiolini M 2006 The G protein-coupled receptor GPR30 mediates the proliferative effects induced by 17 beta-estradiol and hydroxytamoxifen in endometrial cancer cell. Molecular Endocrinology 20 631-646. (doi:10.1210/me.2005-0280)

Watson RT \& Pessin JE 2001 Subcellular compartmentalization and trafficking of the insulin-responsive glucose transporter, GLUT4 Experimental Cell Research 271 75-83. (doi:10.1006/excr.2001.5375)

Received in final form 7 June 2017

Accepted 20 July 2017

Accepted Preprint published online 20 July 2017 http://jme.endocrinology-journals.org DOI: 10.1530/JME-17-0041
๑ 2017 Society for Endocrinology Printed in Great Britain
Published by Bioscientifica Ltd 